\title{
Pericle Martinescu: el escritor exiliado en su propio país "Mi vida en un mar de silencio y de soledad"
}

\author{
Luminiţa MARCU \\ Departamento de Literatura Rumana \\ Universidad de Bucarest \\ luminitzamarcu@yahoo.com
}

\section{RESUMEN}

Con la implantación del régimen comunista en Rumanía, numerosos intelectuales y representantes de la cultura rumana fueron perseguidos, encarcelados o marginados. En este artículo se tratará el caso del escritor Pericle Martinescu que, en vez de exiliarse como hicieron otros, prefirió permanecer en su país, aunque se vio apartado de la vida pública y su carrera literaria fue interrumpida. Su diario, escrito a escondidas, es un valioso testimonio de las vivencias de los intelectuales rumanos durante este periodo.

Palabras clave: Rumanía, régimen comunista, Pericle Martinescu, literatura rumana.

Pericle Martinescu: the exiled writer in his own country. "My life is a sea of silence and solitude"

\begin{abstract}
With the arrival of the communist regime in romania, many intelectuals and representatives of the romanian cultura where persecuted, incarcerated or marginated. This article deals with the case of writer Pericle Martinescu who, instead of choosing exile as others made, prefered to stay in his country, although he was put aside of public life nad his literary carrer was interrupted. His diary, wrote in hidding, is a valuable testimony of the lifes of romanian intelectuals during the period.
\end{abstract}

Key words: Romania, communist regime, Pericle Martinescu, romanian literature. 
E1 27 de octubre de 1950, tres años después de la instalación oficial del régimen comunista en Rumanía, un escritor rumano de 39 años, residente en Bucarest, escribía en su diario:

Ayer Luchi me preguntó qué tanto escribía en ese cuaderno que "escondo". Cuidado, no vaya a pasarte lo que a Spina en cuya casa, después de arrestarle, encontraron unas anotaciones y poemas contra el régimen, que empeoraron su situación. Es verdad, podría ocurrirme. Tomaré medidas para esconder aún mejor este cuaderno. Escribo cada vez más, con más miedo, pero tampoco puedo ya renunciar. Ésta es la única válvula a través de la cual respiro la libertad. Y sin libertad, me ahogo. (Martinescu 1997) ${ }^{1}$

El caso de este escritor, Pericle Martinescu, que escribía su diario a escondidas, incluso de su mujer (como contaba en una entrevista ${ }^{2}$ en 2004, justo antes de su muerte), no fue singular durante el periodo de dictaduras sucesivas que marcaron los años 1947-1989 en Rumanía. Uno de los más interesantes es el de Lena Constante ${ }^{3}$, artista visual y escritora que fue encerrada en la cárcel durante ocho años, a los que siguieron otros muchos de completa marginación, tanto social como cultural.

Otra personalidad fascinante de la cultura rumana que sufrió un largo encarcelamiento -trece años- es Nicolae Steinhardt. Liberado en 1964, empezó a escribir un diario. Terminada la primera versión, los servicios secretos del régimen comunista se lo confiscaron. Lo mismo pasó con la segunda versión que Steinhardt escribió. Sin renunciar a sus memorias, Steinhardt redactó una tercera versión que fue publicada en 1991, después de su muerte 4 .

Se trata, en todos estos casos, de gente que quedaba fuera del espacio público por motivos puramente políticos: gente que estaba encerrada en las cárceles comunistas; gente que había huido del país, eligiendo el camino del exilio; intelectuales que, aun viviendo dentro de las fronteras de Rumanía, no tenían acceso a publicaciones, revistas, editoriales (pues todas estaban bajo un fuerte control político y su financiación correspondía exclusivamente al estado). Estos últimos, que siguieron viviendo en Rumanía, eran escritores que o bien eligieron quedarse en silencio, o bien escribieron a escondidas, tomando incontables precauciones. La mayoría de sus escritos llegaron a ser publicados después de la caída del comunismo y, en muchos casos, después de la muerte del propio autor.

Pericle Martinescu es menos conocido, no ha sido todavía traducido al español y su caso es menos dramático porque no fue encarcelado durante el régimen comunista, pero fue totalmente aislado. Su carrera literaria, iniciada en los años 30, al lado de los ya famosos Mircea Eliade o Emil Cioran, fue brutalmente interrumpida. Peri-

\footnotetext{
1 Todas las citas han sido traducidas del rumano por Laura Tudoras.

2 Fue entrevistado por Joaquín Garrigos en noviembre de 2004, entrevista publicada en la revista Bucurestiul cultural, suplemento 22, núm. 15-16, 2005.

3 Su libro La evasión silenciosa se publicó en España en 2009 por la Editorial Bassarai, con traducción de Francisco Javier Marina.

4 El libro, traducido al español por Viorica Pâtea y Fernando Sánchez Miret, fue publicado en España en 2007 por la Editorial Sígueme.
} 
cle Martinescu era licenciado en Filosofía por la Universidad de Bucarest. Antes del comunismo, escribía en todas las revistas culturales importantes de la época, Revista Fundatiilor Regale, Vremea, Universul literar, Romania literara. Había publicado su primera obra en 1936, la novela Los adolescentes de Brasov y luego, un libro de poemas en 1941. Una vez instalado el régimen comunista, su voz pública fue silenciada hasta 1966, cuando consiguió por fin publicar una monografía sobre un escritor rumano de siglo XIX, y más adelante, un libro de ensayos en 1973. Murió en 2005, con 94 años de edad. Su diario, escrito a escondidas fue publicado en 1997 por una pequeña editorial, Vitruviu, de Constanza.

Pericle Martinescu escribió este diario casi continuamente, empezando en 1936, siendo los más interesantes testimonios los fragmentos escritos al principio del régimen comunista. Es una de las más fieles y sugerentes declaraciones de aquella época, escritas por un personaje de la vida literaria rumana, un personaje que se hunde poco a poco en un aislamiento que llega a ser casi un exilio interior.

A principios de 1948, Pericle Martinescu todavía trabaja en el Departamento de Prensa del Ministerio de Información, puesto que ocupaba desde antes del cambio político, es decir, antes de que Rumanía se transformara en república. Una de las primeras notas menciona el aislamiento progresivo del mundo cultural rumano, aislamiento que comienza con la prohibición de la distribución de prensa extranjera en Rumanía. Cabe mencionar que la intelectualidad rumana estaba en aquel entonces muy bien comunicada con la prensa europea, especialmente con la francesa. A menudo, en la prensa rumana se publicaban crónicas sobre las novedades literarias del mercado editorial francés.

Hoy han caído en mis manos unas cuantas revistas y periódicos franceses confiscados por la censura en correos y traídos a la sede de la Dirección de Prensa, donde se guardan en el archivo. Los he disfrutado con ansia y me he enterado de novedades acerca de lo que ocurre por el mundo. Leyéndolos, me he dado cuenta de que el mundo sigue vivo, que la gente piensa libremente, disfruta de los juegos del espíritu -no está enterrada como nosotros entre montañans de eslógans y literatura "comprometida". ¡Qué lejos estamos del resto del mundo, qué odiosas fronteras existen entre nosotros y el mundo literario de occidente! Cuando te cae entre las manos una revista, tienes la sensación de haber tocado el cielo azul, un pedazo del horizonte ilimitado de la libertad. (Martinescu 1997)

Un año después, Pericle Martinescu escribe sobre la nueva realidad cultural rumana:

Mi cumpleaños. Cumplo 39 años. Me hubiera gustado celebrarlo, pero no tuve ganas. He fingido olvidarme de este detalle biográfico. Y lo hubiera olvidado de verdad, si, al abrir los periódicos y las revistas aparecidos hoy, no me hubiera topado con artículos y estudios que cubren páginas enteras sobre el poeta A. Toma, que cumple 75 años. Desde Eminescu, A. Toma es el poeta más grande de "nuestro pueblo”. ¡Bravo! Qué rápido ascienden los poetas en la RPR [República Popular Rumana] [...]. Con motivo de dicha celebración, la Editorial del Estado (director general A. Toma) ha publicado un volumen que recopila los versos de entre 1894 y 1949 del homenajeado, con una tirada de veinticinco mil ejemplares 
a cien leus, lo que viene a ser, de golpe, veinticinco millones de leus (es decir, una casa en el centro de la ciudad) destinados al autor. A lo que se le añade su sueldo de la Academia, de la Editorial del Estado y de otras instituciones filantrópicas "pour les notres". En todo este tiempo, nuestros grandes poetas, Arghezi, Bacovia -por no mencionar a los más jóvenes- luchan con la más profunda miseria. (Martinescu 1997)

El poeta nacido el mismo día que Pericle Martinescu, A. Toma, es uno de los héroes de la época. A. Toma, aprovechando su puesto como director de la editorial, publicaba sus propias obras poéticas. Salta a la vista la cantidad de dinero ganado por los autores apreciados por los dirigentes comunistas. Todos los demás, entre los cuales destacan poetas importantes como Tudor Arghezi o George Bacovia, permanecían completamente aislados. Cabe mencionar la situación de exiliados interiores de estos dos poetas. Tudor Arghezi vivía en su casa de Martisor, en las afueras de Bucarest, sobreviviendo gracias a la venta de las frutas que producía en su propia huerta. No pudo publicar nada bajo su nombre real hasta 1955, cuando por fin apareció un poemario de una temática apreciada por el régimen comunista. George Bacovia, poeta del Simbolismo, a pesar de sus opciones políticas izquierdistas -publicó en 1946 un volumen de poesía intitulado Estrofas burguesas- era rechazado bajo la acusación de decadencia.

Otro párrafo del diario de Pericle Martinescu explica otro tipo de exilio, el que sufrieron los campesinos que poseían grandes superficies de tierra antes del comunismo. Por ser dueños de tierras, estos campesinos fueron acusados de pertenecer a la clase explotadora y, en consecuencia, expulsados de sus propias casas y pueblos.

En la tarde del 2 de marzo recibí una llamada: mi padre había muerto. La noticia no me sorprendió, la esperaba. Mi padre era mayor, estaba muy amargado... [...]. Vivía solo, en un cuartucho como una celda, en una calle y en un patio sórdido, en Constanza, en el barrio de los Talleres. Encendía solo el fuego en la estufita, cortaba madera, comía donde su casera. Lo veía una o dos veces al mes, pero se encontraba más a menudo con gente del pueblo que, o bien pasaba por su casa, o bien se la encontraba en Obor, adonde iba adrede para ver a alguien, le traían alguna noticia -nunca buena- de su casa. Hacía un año que no tenía permiso para entrar en el pueblo, para ver a su familia, para respirar el aire que había respirado toda la vida, para vivir en los lugares donde había vivido durante décadas. El 5 de marzo de 1949 le habían echado de su casa, sólo con lo que llevaba puesto -y junto con él a toda la familia (nueve personas, de las cuales cinco nietos, el mayor de 12 años, el pequeño de 6 semanas)- pasando, de la noche a la mañana, de hombre bien avenido a muerto de hambre, por el hecho de seguir teniendo 50 hectáreas de tierra. Su tragedia fue también la de otros, siendo hoy tan bien conocida en nuestro país que huelga insistir en ello. No creo que haya gente más perseguida que estos campesinos que durante toda una vida no han pensado, quizás, más que en trabajar para tener una muerte digna, en sus casas, en sus pueblos, donde han construido escuelas, iglesias, carreteras y otras cosas. Y precisamente ellos se ven abocados a morir solos, como unos vagabundos, desconocidos y sin nadie que les cuide. (Martinescu 1997) 
Un año más tarde, el peligro se agudiza y el miedo al ser detenido le va enloqueciendo poco a poco. A menudo, el autor anuncia el imprescindible final del diario:

Concluyo estas líneas con la esperanza de que un día verán la luz, sacadas del agujero en el que las escondo ahora ${ }^{5}$, y de que puedan ser leídas sin el temor de que alguien espíe en la ventana, sin el temor de que "por la noche" venga la Securitate [la policía secreta] para detenerme, descubriéndolas entre los libros que quién sabe en qué van a quedar. Hoy es 28 de marzo. Cada noche me acuesto con el sentimiento de que al día siguiente no me despertaré en mi cuarto. De hecho, les estoy esperando. Cada día en libertad es una gran victoria, en esta preciosa y trágica primavera, en la que todo el mundo llora y teme. (Martinescu 1997)

Pericle Martinescu, despedido del trabajo que tenía en el Ministerio por no haber hecho suficientes compromisos para el régimen, se queda en paro a partir de 1952. Menciona en un pie de página que, después de tal año, nunca jamás en su vida consiguió otro trabajo como funcionario público. Pericle Martinescu, Licenciado en Filosofía, teniendo una amplia experiencia periodística, traductor de varios idiomas, se quedó sin trabajo fijo a los 40 años de edad. A partir de ese momento, vivió de los ingresos de su mujer, que trabajaba de funcionaria, y de esporádicas traducciones que le encargaban (muchas veces firmando con otro nombre). El matrimonio reside en un barrio periférico de Bucarest. Este alejamiento físico voluntario constituye un símbolo evidente de su condición como exiliado dentro de su propio país. Un amigo les visita:

Venía por primera vez a mi casa. Estaba sorprendido por lo lejos que vivía, en un barrio sin ninguna comodidad. [...] La verdad es que no me encontraba a gusto aquí, que querría vivir en la ciudad, en el centro, como lo había hecho siempre hasta 1945. Hubiera tenido, por supuesto, la posiblidad de encontrar un piso en el centro, pero no pensé en mudarme. Mi actual domicilio no es otra cosa que una protesta contra estos tiempos. Mientras duren, no renunciaré a esta forma de protesta. Y los años pasados aquí -se cumplen ocho ahora- son los años más infelices, sobre todo si pienso que, después del matrimonio, hubieran podido ser los años más felices de mi vida. (Martinescu 1997)

Un emocionante fragmento de su diario, fechado el 11 de febrero de 1952, habla de "el mar de silencio y de la soledad", quizás una de las más sugerentes metáforas sobre la condición del escritor exiliado dentro de su propio país:

Desde los 36 años mi vida se ha convertido en un Mar del Silencio y de la Soledad... Me siento como un condenado, sí. Desde hace al menos cinco años, desde que nuestro mundo de aquí ha cogido el camino que sigue ahora, siento como se hace todo más oscuro a mi alrededor, como se estrecha la célula entre cuyas pare-

\footnotetext{
${ }^{5}$ En una entrevista en la revista Romania literara, núm. 10, 2010, Pericle Martinescu contaba que efectivamente escondía el cuaderno donde escribía este diario "en nuestro jardín, bajo tierra".
} 
des me veo obligado a vivir y cómo se vuelven más pesadas, con cada día que pasa, las cadenas que me atan el alma y el espíritu, [...] la miseria de una época de brutalidad y de fango, que hace aún más difícil de soportar una "vida suplementaria". No estoy hecho para semejante época negra y mezquina. Y si vivo, sin embargo, se debe sólo al destino, al que me abandono por completo. No obstante, esta situación de "condenado a la muerte civil" ya no me aterra. (Fui despedido también de Calauza bibliotecarului ${ }^{6}$, no he vuelto a tener nunca un empleo público. Sólo he conservado la calidad de miembro de la Unión de Escritores). (Martinescu 1997)

\section{BIBLIOGRAFÍA}

MARTINESCU, Pericle (1997): 7 ani cit 70, Jurnal. Constanza: Editura Vitruviu.

- (2003): "Ma consider in intrecere cu fostul presedinte Ronald Reagan", entrevista con Pericle Martinescu de George Arion. Romania literara, núm. 10.

- (2005): “Tinerii din anii 30", dialog intre Pericle Martinescu si Joaquín Garrigós. Bucurestiul cultural, núm. 15-16.

\footnotetext{
${ }^{6}$ Una pequeña revista, sin gran importancia, "La guía del bibliotecario".
} 